\title{
CALPE Y AL-ASKAR (ALICANTE). SOBRE EL HÁBITAT MEDIEVAL DEL PEÑÓN DE IFACH Y AL-ASKAR O MADINAT AL-ASKAR
}

Basilio Pavón Maldonado*

\section{CALPE-IFACH}

El último escrito histórico-toponímico del Calpe alicantino creo que son unas pocas páginas del profesor Vallvé Bermejo incluidas en su trabajo de ingreso en la Real Academia de la Historia, La conquista árabe de España, Toponimia y onomástica ${ }^{1}$. Se ocupa ese autor del monte "Calpe", referido al Peñón de Gibraltar, según identificación de algunos autores clásicos. Pero el término "qalb" como topónimo hispánico aparece referido a Gibraltar en escritos geográficos e históricos árabes. Para al-Himyari e Ibn Galib "qalb” es sede o capital de la cora de Morón (Sevilla). Vallvé sugiere la posibilidad de encontrarnos con un topónimo prerromano, Calpe, con la acepción de monte; luego, añade, tenemos el Peñón de Gibraltar o Calpe, el Qalb de Moròn y Calpe de Denia o Alicante con su imponente Peñón de Ifach; además, fuentes árabes citan lugar de Qalb o Kalb, en la cora de Tudmir, cerca de Denia y que hay que identificar con la actual Calpe. Hasta aquí el escrito de Vallvé Bermejo. Idrisí sorprendentemente no dice nada de Calpe, y al-Zuhri, también del siglo XII, da escuetas líneas referidas a la pesca del atún en el lugar que se conoce con el nombre de Kalb, "que está entre Denia y M.r. y r.”.

Sea el término Calp -para los árabes la voz qalb- monte o capital de cera, lo cierto es que sirvió para denominar dos núcleos de población o hábitats al pie o cerca de un eminente cerro de prestigio clásico, Gibraltar y Calpe, binomio éste por tanto que encierra sugestivas resonancias históricas y, en consecuencia, tentadoras reflexiones mirando el tema desde el siglo XV-

\footnotetext{
* $\quad$ C.S.I.C., Madrid.
}

1. J. VAllvé BermeJo, Nuevas ideas sobre la conquista árabe de España. Toponimia y onomástica, Madrid, 1989. 
XVI, en que surge la actual población de Calpe, hacia atrás. Concretamente en el Calpe alicantino las prospecciones arqueológicas han proporcionado importantes restos de construcciones y cerámica ibero-romana, las primeras cerca del peñón de Ifach, junto a la playa y la cerámica y algo de muros en el mismo istmo del Peñón. Corre la tradición de ser Calpe, junto a Ifach, fundación fenicia-griega; con los romanos hábitat importante del que son las ruinas junto al mar dadas a la luz en 1797 por Cavanilles, "los Baños de la Reina Mora", que las últimas excavaciones han ampliado con nuevas casas y pavimentos. Últimamente Enrique Llobregat ha señalado que de los siglos V o VI de nuestra era e incluso más tarde hay un fortín, muy reducido; se refiere al poblado de la parte superior del istmo de Ifach $^{2}$.

Centrado en el Peñón de Ifach discurrirá nuestro estudio siempre dentro de la Edad Media, árabe y cristiana, si bien sin perder nunca de vista que el peñón alicantino tuvo ya cierto protagonismo en épocas clásicas dada su insólita personalidad orográfica adentrada en el mar y relacionada por un istmo con la tierra; su misma configuración natural con cuatro caras diferentes, especie de cuenco invertido, algo cavernoso de la parte de tierra a la vez que con aspecto de fortaleza natural, donde, en tierra firme, en tiempos pasados y hoy aparecen restos cerámicos, testimonios irrefutables de un hábitat ibero-romano, árabe y de repoblación cristiana, un ejemplo más en el dilatado paisaje de al-Andalus de acumulación de culturas en un mismo territorio de no más de cuatro hectáreas. Tal extensión superficial aún se ve acotada por muros torreados deslizándose pendiente abajo con rellano o meseta en la parte más inferior. Esto aparte de que la cumbre del Peñón, a 329 metros sobre el nivel del mar, es formidable atalaya natural donde quizá desde la época romana o árabe pudo haber torre vigía de la que se tienen noticias a partir del siglo XIII-XIV. El Peñón de Ifach y el opuesto de Toix, en medio de los cuales está el Calpe actual, eran las puntas marítimas en las que tierra adentro arrancaba un territorio montuoso y muy quebrado que los documentos cristianos medievales denominan "término del castillo de Calpe"; ese castillo identificado con las ruinas existentes sobre el eminente peñasco de Mascarat, término éste que merecerá ciertas reflexiones en el presente estudio. Aquel hoy despoblado de Ifach nunca alcanzó título de castillo; es conocido como lugar fortaleza o población con muros y torres, en definitiva en los tiempos modernos, "Calpe el Viejo". Tales coordenadas nos permiten adentrarnos en nuestro estudio del Peñón de Ifach.

En el aspecto arqueológico ha sido objeto de estudio por el padre Belda, Martínez Martínez, C. Aranegui y Bazzana ${ }^{3}$ y, por último, Enrique Llobre-

2. E.A. Llorregat ConesA, «Una aproximación a la historia antigua de Calpe», Revista Calpe, 9, 1983.

3.

C. Aranegui, «Materiales arqueológicos del Peñón de Ifac (Calpe)», Saguntum, 9, pp. 49-59, 1973; «Introducción a la problemática de las imitaciones en cerámica de barniz negro del 
gat $^{4}$. A nivel ilustrativo referente a los restos arqueológicos o arquitectónicos del istmo, Laborde hizo un interesante dibujo o grabado con restos de la muralla que en la parte baja deja ver cuatro torres y una quinta interior que se puede identificar con la torre de un templo que allí hubo desde el dominio de esta tierra de Roger de Lauria. Luego, ya en nuestro tiempo, año 1980, Aranegui publicó un importante plano que aprovecha y matiza Bazzana en su estudio ${ }^{5}$, viéndose en la muralla el número aproximado de torres que aún existen. A partir de esos estudios e ilustraciones los nuestros ahora intentan matizar o enriquecer el tema medieval siempre viéndolo con perspectiva arábiga y cristiana o de repoblación, poniendo a veces en cuarentena, sin salirnos de ese ámbito histórico, planteamientos, tesis o hipótesis defendidas por Bazzana.

Dice este autor al final de su breve estudio sobre las murallas del despoblado de Ifach que estamos ante una construcción califal cuya existencia se explica por las condiciones geográficas excepcionales que ofrece el lugar y su posición marítima y terrestre, en la ruta de Alicante hacia Denia, ruta cuyo trazado debía contornear las mismas montañas de las sierras de los Prous y de Artama, pasando por la proximidad de Ifach. Bazzana publica el plano referido con el recinto amurallado medieval de cuatro torres más parte de muro travesaño en la parte alta, identificado con el de época tardorromana reconocido en jornadas arqueológicas anteriores. Bazzana fecha la muralla envolvente del hábitat en el siglo X y quizá en el XI haciendo hincapié en la fábrica de mampostería con huellas de encofrado tipo árabe de 0,69 a 0,71 de altura; asimismo, hace descansar su tesis en una torre del frente NE. con sillares en la parte inferior o zócalo en parte en talud, con aparejo "regular" de factura musulmana de tradición califal, aparejo de calidad que raramente se encuentra en la región valenciana y muy frecuente en la región de Granada (?); tales son las consideraciones del autor francés.

De la repercusión de ese estudio de Bazzana sólo conozco unas líneas de Carmen Barceló Torres que dicen: "Castillo (?) de Ifac, s. X o principios del XI, según criterio de Bazzana, 1980, Callosa de Segura y Orihuela, s. X y XI (Azuar)”“. Dado por válido el criterio de Bazzana es novedoso descubrir una muralla califal en la provincia de Alicante, adelantándose a Denia (s. XII), en que como es sabido sólo ha sido detectada muralla y torre tardocali-

Peñón de Ifac», Revista del IDA, 22, pp. 51-57, 1977; ARANEGUI y A. BAZZANA, «Vestiges de structures defensives d'époque romaine tardive et d'epoque musulmane au Peñón d'Ifach (Calpe, Province d'Alicante)», Mélanges de la Casa de Velázquez, XVI, pp. 421-436, 1980.

4. Llobregat CONESA, op. cit.

5. ARANEGUI y BAZZANA, op. cit.

6. C. Barceló Torres, Minorías islámicas en el País Valenciano. Historia y dialecto, Valencia, 1984, p. 165. 
fal en Alponte ${ }^{7}$, pero aquí el aparejo de sillares es de incontestable identidad omeya tipo cordobés muy distinto del aparejo de torres de la muralla de Ifach que apuntan más, en nuestro criterio, a época medieval cristiana o mudéjar según argumentos que más adelante veremos; pero vaya por delante la presencia en la referida torre de Ifach, que estudia Bazzana como omeya, de un pequeño talud en el zócalo de sillares, modalidad nada usual en lo conocido árabe del siglo $\mathrm{X}$ y sí en cambio en el siglo XII almohade fuera de Sharq al-Andalus, y en fortalezas cristianas comprendidas entre el siglo XIII y XV, precisamente de la zona alicantina; ese talud o "alambor" se deja ver en la torre de Santa Catalina del castillo de Jijona (siglos XIII-XIV), atalaya torre de Vaillos, torre atalaya cristiana de Cocentaina, erigida al parecer por Roger de Lauria, precisamente el reconstructor, como se verá, de Ifach, y torre principal de Forna, entre otros ejemplos.

Lo ideal en este tipo de temas es contar con la ayuda de la cerámica rastreada en el lugar objeto de estudio, si es que la hubiere. En el istmo de Ifach han salido y siguen encontrándose buen número de fragmentos cerámicos árabes de tipo común y algo de vidriado, verde, melado y marrón con trazos negros de manganeso, pero nada hasta ahora de cerámica doméstica tipo califal, de verde manganeso y de "cuerda seca" que aparece en algunos enclaves de la zona, Bernia, Gardiux, Alquería de Lambert y Enginent. En Ifach, fragmentos de tapaderas, de tinajas y ollas, barros con trazos de engobe negro y rojizo, todo de alfares musulmanes o de tradición musulmana que llevan a pensar que efectivamente este lugar fue asiento de poblado árabe al resguardo de la roca, utilizándose muy probablemente el fortín antiguo de la parte superior. Además, salen en buena cantidad fragmentos de teja moruna. A partir de ese fortín, que para Llobregat funcionaría en el siglo V-VI, el poblado árabe debió extenderse pendiente abajo hasta alcanzar la mesetilla inferior, donde he podido rescatar cerámica vidriada verde manganeso tipo repoblación, del siglo XIV-XV. El problema es saber cómo sería, si la tuvo, la muralla primitiva envolvente de todo ese hábitat arábigo de naturaleza básicamente rocosa. Como las fuentes cristianas de las que haremos uso más adelante hablan de obras importantes allí realizadas prácticamente ex novo, obras de reforzamiento con torres, cabe defender un hábitat árabe anterior rústico o provisional de época incierta al que los cristianos añadieron muralla torreada por voluntad real de repoblar el lugar, que en nuestro criterio nada tiene de califal, tesis avalada no ya por las facturas de las fábricas constructivas que se ven in situ sino también por los fragmentos de cerámica vidriada de repoblación expresada que, por cierto, no deslumbran por su abundancia. Se debe contar con que todo el terreno ha sido muy removido

7. A. Ribera i Gómez, «El Castell d'Alpont (Valencia)», Actas I Congreso de Arqueología Medieval Española, Zaragoza, 1986. 
en los últimos tiempos, acumulándose los escombros en la mesetilla baja. En los tiempos en que se lleva a cabo ese reforzamiento, entre los siglos XIII y XIV, no eran extraños los encofrados heredados de los árabes, por tanto, creo que no se puede adjudicar necesariamente esa técnica constructiva a la etapa califal defendida por Bazzana. En Ifach la mezcla empleada es un mortero consistente al parecer sin revoco al exterior y huella por el interior de fajas rehundidas del encofrado de la altura expresada, cuya presencia en al-Andalus se pude remontar a la época omeya, como luego se verá.

Volviendo al plano de Ifach interpretado por Bazzana, se dan en él 4 torres; el nuestro de ahora, que respeta el trazado de la muralla de aquél, tiene 6 torres, la número 2 prácticamente destruida, con restos de sillares de la base, y la número 6 con los sillares in situ que Bazzana fecha en el siglo X; la número 3 en el plano de este autor es hipotética y en la 5 , algo esquinera, debió haber una puerta, tal vez otra junto a la torre 2, por donde ahora se accede al recinto. Lo de los sillares es manifiestamente cierto que existían como zócalo en todas las torres, de planta muy apaisada; algunos arrancados fueron reutilizados en edificios modernos de los aledaños, otros aprovechados en la muralla erigida estos años junto a la torre 2, viéndose sillares con redientes en forma de angulillos para mejor trabazón, modalidad prácticamente ausente de muros omeyas de Levante y Andalucía mientras se prodiga en lo cristiano. Tienen los sillares dimensiones de 0,70 por 0,20 o 0,30 de alto, bastante apaisados, más propios, por lo tanto, de los siglos XII, XIII y XIV que del siglo X. No se ve alternancia de sogas y tizones tipo omeya. Los paramentos del interior de la muralla tiene revoco de estuco que se ve en la parte de las torres 1 y 5 , habitual lo mismo en la dominación musulmana que en la cristiana.

De nuestro estudio se desprende que no sería precisamente este lugar de Ifach elegido como acampada de los ejércitos omeyas que desde Andalucía se dirigían por la costa levantina a la Marca Superior o con motivo de campañas de castigo contra los rebeldes de la cora de Tudmir, según testimonios de Ibn Hayyan en el Muqtabis V. ${ }^{8}$ Tal vez el lugar elegido estuviera tierra adentro, porque lo que parece intuirse del Peñón de Ifach es que debió de quedar un poco al margen de todo acontecer histórico quizá por la presión de las razzias marítimas de los berberiscos o piratas del mar que obligaban a la población a adentrarse en zona serrana del interior o en sus mesetas de las estribaciones. En este sentido orienta bastante el lugar del interior elegido para construir el castillo de Calpe, en Mascarat, castillo protagonista frente a Ifach en la larga etapa cristiana hasta el siglo XVI.

8. Ibn Hayyan, MuQtabis. V. Crónica del califa Abd al-Rahmán III an-Nasir entre los años 912 y 942 , trad., notas e índices por M.J. ViGUERA y F. CORRIENTE, Zaragoza, 1981, p. 122. 
Las fuentes cristianas medievales ya expuestas e incluso razonadas con buen criterio por Vicente Llopis en su obra Calpe son definitivas en lo que se refiere al despoblado-poblado de Ifach. Reinando Pedro III, en 1282, este soberano ordena a los habitantes del término de Calpe que tras su decisión de construir el lugar de Ifach éstos debían instalarse allí emprendiendo las obras necesarias para ello ${ }^{9}$. Añade Llopis que las obras reales no se llevaron a cabo, aunque años después la familia Lluria conseguirá el repoblamiento de Ifach por poco tiempo. Tras este fracaso de Pedro III, Roger de Lluria o Lauria en 1298 solicitaba permiso para construir en Ifach un lugar que contara con fuertes murallas y defensas. El rey desde Nápoles le daba permiso para ello $^{10}$. Habla Llopis de los restos de una iglesia en la nueva población fundada por Margarita de Lauria, torre que pudiera identificarse con la más espigada que se ve en el grabado de Laborde. Es importante subrayar que los documentos cristianos anteriores a 1282 no dicen nada de Ifach quedando sólo referenciados el castillo y villa de Calpe y su baile y alcaide ${ }^{11}$. Coinciden todos los historiadores alicantinos en los grandes desperfectos o destrucción que padeció el poblado de Ifach a causa de las guerras de los Pedros, lo que obligaría al monarca aragonés Jaime II a autorizar al conde de Denia replantear las fortificaciones de Ifach o si lo cree más conveniente demolerlas totalmente, con la finalidad de que el lugar fuera más fácilmente defendible (?) ${ }^{12}$. De aquí en adelante y hasta el siglo XVI fracasa al parecer todo intento de poblar el lugar que desde esa centuria pasaría a ser Calpe el Viejo con todo su bagaje arqueológico de hábitat ibero-romano, árabe y cristiano.

Tales informaciones a nuestro juicio no dejan lugar a reconocer en Ifach obras militares califales como las propuestas por Bazzana, las que desde el punto de vista arqueológico pusimos en cuarentena. La muralla y sus torres fueron hechas en una misma jornada constructiva y es indefendible que en la época de Roger de Lauria se procediera a rehacer o reconstruir obra militar árabe del siglo X. En nuestra opinión el poblado árabe que allí hubo, refrendado en parte por la cerámica, era hábitat desguarnecido de la parte de tierra, a lo sumo con muralla endeble de tierra o tapial suplantada por la muralla erigida en 1289. El regazo del peñón pudo abrigar en todo tiempo población estable aunque insegura por causa de las agresiones de los piratas del mar que allí encontraban lugar idóneo para fondear con comodidad.

9. V. Llopis, Calpe, 1975, p. 51.

10. Ibidem, pp. 56 y 57.

11. J. MartíneZ Ortiz, Alicante y su territorio en la época de Jaime I de Aragón, Alicante, 1993.

12. V. LlOPIS, op. cit., p. 61. 


\section{AL-ASKAR}

Ya expusimos en líneas anteriores nuestro interés por el término "Mascarat", lugar donde sobre agresivo peñasco se levanta el verdadero castillo de Calpe a juicio de los documentos medievales. La fortaleza está en lugar estratégico básico para todo tiempo, donde los árabes debieron tener baluarte vigía luego muy reformado a partir del reinado de Jaime I. Hay allí amasijo o conglomerado de obras en el que no vamos a entrar ahora. Mascara o Mascarat es una voz que incita a verla como árabe relacionándose en principio con al-'askar equivalente a campamento, con $\mathrm{M}$ delante, tal vez por la asociación del genérico árabe Umm y el apelativo al-askar con la acepción, según Lévi-Provenzal, de ciudad principal o metrópoli, genérico estudiado por Félix Hernández en los casos extremeños de "Umm Ya'far = Mojafar" y " Umm Gazala = Magacela", denominaciones ambas de castillos sobresalientes de época omeya ${ }^{13}$; en el caso que nos entretiene se trataría de campamento, ciudad campamento o campamento principal con homónimos en el Mascara de la región de Orán -Ma'askar- ${ }^{14}$, otro de la provincia de León, Almazcara, y tal vez el Mascaraque de la provincia de Toledo, en el camino de Consuegra a Toledo pasando por Mora y Almonacid. Y en Zaragoza el campamento o ciudad campamento de asedio que funda Abd al-Rahmán III en 935, según relato del Muqtabis V de Ibn Hayyan y también de al-Udri ${ }^{15}$ : los términos empleados para ese campamento son "dar", "muqani", "madina", "mahalla", "manzil” y "mu'askar". Pero estas reflexiones chocan con el dicho popular de que el Mascarat alicantino viene de una persona extraña, tal vez morisca, que habitó en esos parajes en el siglo XVII. Desde luego esa voz no suena en los documentos medievales cristianos suplantada como vimos por la de Calpe y el "término del castillo de Calpe”. Era esta fortaleza junto con las de Denia y Bairén la más principal de la costa de esta parte, las tres de reconocida posición estratégica y las dos últimas de raíces islámicas probadas. Otra cuestión, como ha señalado Barceló Torres, es el límite meridional de la cora de Valencia que esa autora pone en la línea Callosa d'En Sarrià, Mascarat y Calpe, como parece inferirse, dice, de los textos árabes ${ }^{16}$; es decir, esos lugares serían fronterizos. En realidad, lo que me lleva a subrayar ahora al-'askar o Mascarat es la descalificación como califal del despoblado de Ifach, cuyas murallas hacen pensar fácilmente en un hábitat campamento estable o itinerante en zona costera que

13. F. HERnÁNDEZ GIMÉNEZ, «La Kura de Mérida en el siglo X», Al-Andalus, X, 1960, pp. 335-340.

14. Encycloèdie de l'Islam. Nouvelle édition, t. VII, 1993, pp. 264-265.

15. V. MuQtQBis, F. de la GRANJA, La Marca Superior en la obra de al-Udri, Zaragoza, 1967, J.A. SoUTO LASALA, en La Marche Supérieure d'al-Andalus et l'Occident Chrétien, Madrid, 1991.

16. C. BARCELÓ, op. cit., p. 163. 
como vía o calzada árabe se la da de lado en la actual historiografía, no así Bazzana si se acepta su tesis califal de Ifach.

Respecto a la voces Mascarat o al-'Askar las fuentes árabes dejaron testimonio dentro de Sharq al-Andalus de la segunda, tema en el que entro como tantos otros lo han hecho, cada cual con sus puntos de vista y a partir de las siguientes informaciones ya harto conocidas. El Muqtabis $V$ de Ibn Hayyan, con motivo de la campaña de castigo contra Pamplona del año 924, protagonizada por Abd al-Rahmán III, habla de una madinat al-Askar de los alfoces de Valencia, término -al-'Askar- que Lévi-Provençal identificó con Alasquer, despoblado de Alberique a 45 kilómetros de Valencia; el ejército omeya en ese lugar sometió al rebelde Ibn as-Sayj para lo cual combatió sus fortalezas y holló sus llanos ${ }^{17}$, si bien al-Udri dice que ese personaje, que era señor de Callosa, se sublevó en ésta y que fue sometido en Alicante ${ }^{18}$; noticia manifestada antes por el mismo Ibn Hayyan en la campaña de Abd al-Rahmán III del año 928, donde se dice que "cayó Callosa, Alicante con sus castillos y alcazabas, base de los Banu-s Sayj""; ; a continuación, cayó Alcira de la cora de Valencia. Y es conocido por las fuentes árabes que en Tudmir en el siglo IX había dos ciudades, Lorca y al-'Askka ${ }^{20}$ con mimbar (Yaqubi); además, al-Udri informa que en la cora de Tudmir había 17 distritos cuyas listas la encabezan Lorca, Murcia y al-'Askar. Al paso de este imbricado cúmulo de datos Vallvé Bermejo trata de poner orden adelantando que pudo haber equivocación o error pudiéndose confundir entre al-Askar de la cora de Valencia y otro campamento del mismo nombre en la cora de Tudmir ${ }^{21}$, autor que no cita a Molina López y Rubiera Mata, quiénes guiados por estas informaciones piensan que la ciudad o lugar de al-Askar pudo estar en Callosa d'En Sarriá, en lugar de Callosa de Segura, que sería, la primera, sede o cabeza del señorío del rebelde Ibn as-Sayj ${ }^{22}$, identificación que se aparta de la vía o calzada de Alicante a Játiva o Vía Augusta del Vinalopó.

En 1995 Franco Sánchez da casi por hecho que al-Askar es Callosa d'En Sarrià que está en los límites de las coras de Tudmir y Valencia. Concluye este autor que los Banu-s-Sayj eran dueños de Callosa d'En Sarrià, Alicante, Callosa de Segura y quizá Albacete, todas junto a la Vía Augusta, menos

17. V. MUQTABIS.

18. E. Molina LóPEZ, «La kura de Tudmir según al-Udri (s. XI)», Cuadernos de Historia del Islam, 4, Granada, p. 81.

19. V. MuQTABIS, Antuña, París, 1937, p. 22.

20. E. MOLINA LÓPEZ, op. cit., p. 73.

21. J. VAllvé Bermejo, op. cit.

22. E. MOLINA LÓPEZ, op. cit., p. 81; M.J. RUBIERA MATA, Villena en las calzadas romana y árabe, Alicante, 1981. 
Callosa d'En Sarrià, centro de la Marina de esta parte ${ }^{23}$. Por último, los textos árabes hablan de dos distritos fiscales, Alcira y al-Askar. Lo último que leo sobre el tema a título de propuesta es que, según Mikel de Epalza, al-Askar, campamento, pudo ser o estar en Murcia o la desaparecida Ilyh de reciente estudio por Pocklington ${ }^{24}$.

Nuestras reflexiones apuntan a que el "Mascarat" alicantino tiene grafía más que aproximada al compuesto "umm-al-askar", como el Almazcara leonés y que no extrañaría mucho localizar en la amplia zona serrana de Almeia y Bernia y a lo largo del curso del río Guadalest una acampada estable o campamento árabe fronterizo con calificativo de madina de época omeya; campamento hoy inexistente y que alargando más nuestras sospechas pudo tratarse de acampada preislámica reutilizada que los árabes bautizaron con el al-Askar o Mascarat. Pudo ser la segunda voz topónimo residual de amplio territorio llamado al-Askar en los siglos IX y $\mathrm{X}$ enclavado en zona montuosa o de serranía de la Marina Baja fronteriza con la Alta y a la vez límite más meridional de la cora de Valencia, y con sede en lugar del río Guadalest, como Callosa d'En Sarrià propuesto por Molina López, Rubiera y Franco Sánchez. Pero ni Callosa d'En Sarrià, cuya fortaleza prácticamente ha desaparecido de la llamada plaza del castillo, ni el castillo roquedo de Mascarat dan testimonios arqueológicos y quizá espacial de un hábitat de los siglos IX y X llamado al-'Askar, ejemplo que se suma a la nómina de ciudades o poblaciones importantes de la cora de Tudmir de ignorada ubicación o identificación difícil, la misma Mula, Blntla, Bqsra e Iyih-Ello, cuatro de las siete poblaciones citadas en el pacto de Teodomiro ${ }^{25}$.

La identificación al-Askar como Callosa d'En Sarrià frente a al-Askar como Callosa de Segura, pese a los restos de castillo de ésta estudiados por Azuar, quien los fecha en el siglo $\mathrm{X}^{26}$, parece lógica por varias razones; primero por ser todo su entorno zona fronteriza y serrana con varios castillos, frente a Callosa de Segura, cuya proximidad a Orihuela y a la misma Murcia la dejan como población importante fuera de juego. En nuestro criterio todo al-'Askar o Campamento en al-Andalus se emplazaba en zona fronteriza. En segundo lugar, por ese mismo motivo parece lógico que la ciudad de al'-Askar y distrito del mismo nombre fueran acaparadores de tierras, alquerías y castillos de la zona montuosa de la Marina Baja cuya capitalidad residiría

23. F. Franco SÁncheZ, Vías y defensas andalusies en la Mancha Oriental, Alicante, 1995, pp. 309-311.

24. M. de EPALZA, en La rápita islámica. Historia institucional i altres Estudis Regionals, Sant Carles de la Rápita, 1993, p. 94, nota 92.

25. E. Llobregat Conesa, Teodomiro de Oriola. Su vida y su obra, Alicante, 1972.

26. R. AzUAR RuIZ, Castellología medieval alicantina, Área meridional, Alicante, 1981, pp. 89-95. 
en la Callosa de esta parte, cabeza que fue en la etapa cristiana de Baronía en la que estarían incluidos lugares y castillos como Taberna; es cierto que en el siglo XIII este Callosa figura como alquería y también como castillo, citándose en el año 126818 alquerías, entre ellas Callosa y Muscayra, término éste que en otros documentos posteriores pasa a ser Muschayra y Mosquera $^{27}$. Pudiera ser ese Muscayra descendiente de "Mu'askar", grafía vista en el Mascara de Argelia, el mu'askar de Zaragoza y Almazcara leonés, en definitiva todos ellos topónimos residuales de al-'Askar, madinat al-Askar o Umm al-Askar citados en los textos de Ibn Hayan y al-Udri. De todas formas los dos Callosas alicantinos han protagonizado equívoco para el siglo $\mathrm{X}$-XI y para los tiempos cristianos; en este último tramo con motivo de las guerras de los dos Pedros se cita un Callosa alicantino ganado por Pedro I de Castilla que algunos autores identifican con Callosa de Segura; y consta, asimismo, Callosa de Ensarría, lugar y todo su entorno seriamente avejentados a consecuencia de esas jornadas bélicas de los Pedros. En el promedio del siglo XIV todo ese territorio del dominio del almirante Bernar de Sarrià era conocido por "Montanyes d'En Sarrià", cedido al Conde de Ribagorza, Infante Pedro, hijo de Jaime II, territorio básicamente enclavado en la Marina Baja, con límites en Relleu, Penáguila, zona norte de Tàrbena, Benidorm y Calpe, ésta de incorporación más tardía junto con el término de Altea, cedidos por la familia Lauria al Condado de Denia, beneficiario último de todo el territorio dominado por el valle de Guadalech y en el que se incluyen castillos importantes como Tàrbena, Penáguila, Relleu, Confrines, Castell Castell, Polop y probablemente el de Guadalech ${ }^{28}$.

Sería por tanto ese territorio una autonomía geopolítica y fronteriza en todo tiempo con línea infranqueable en la de la sierra de Bernia desprovista de pasos naturales. Al igual que en el valle del Vinalopó, la acción de almorávides y almohades suplantó cuanto anterior a ella había en el territorio de Callosa d'En Sarrià, con huellas claras de “almohadización” en los castillos periféricos del Norte, como Ambra, Confrines, Castell Castell, Polop, Guadalest, tal vez Penáguila de las cumbres y atalaya de Mascarat, quedando marginadas Calpe y Altea. Ese Callosa d'En Sarrià como supuesto emplazamiento de la ciudad omeya de al-Askar quedó reducido a cúmulo de alquerías sin más rastro hoy de su pasado árabe primitivo que algún dudoso topónimo: Mascarat y Muscayra. Y quizá algún apellido árabe disperso en la vieja cora de Tudmir, como una señora llamada "Mascarosa" la cristiana, que para Burns pudo ser nombre árabe; o el apellido "Askar" de morisco del

27. J. MARTÍNEZ ORTIZ, op. cit., pp. 81 y 109.

28. J. CAmpón GonZalvo, «Consecuencias de la guerra de los dos Pedros en el Condado de Denia», Anales de la Universidad de Alicante, 8, 1990-1991, pp. 57-68. 
siglo XVI expulsado a principios del XVII de Novelda $^{29}$. En este punto cabría subrayar el topónimo Marcarell de la provincia de Castellón, en Nules ${ }^{30}$. Otro punto que no conviene soslayar es el de los campamentos romanos y árabes de Hispania y al-Andalus. En tierras levantinas García y Bellido reconoció en superficie el romano de Almenara, erigido para el cerco y toma de Sagunto ${ }^{31}$. Es interesante de otra parte que auténticos campamentos califales, como el supuestamente desaparecido de Saktan ${ }^{32}$, de la parte de Extremadura septentrional, fueran llamados medinas, y lo mismo ocurriría con Vascos, en la provincia de Toledo, caso de que este despoblado sea, como así lo creo, a continuación de Izquierdo Benito, la ciudad sin nombre que al-Hakam II funda también en el extremo occidental de la Marca Media, que menciona Ibn Idari $^{33}$; en Toledo la ciudad de la conquista o de la Victoria, un campamento de asedio de Abd al-Rahmán III a las mismas puertas de la ciudad del Tajo; lo mismo en la conquista de Zaragoza del año $935^{34}$. Estos recintos militares con aspiraciones de medina tienen otros ejemplos dentro de la Marca Superior, Plá d'Almatá y Alguaire en Lérida ${ }^{35}$, y Olite en Navarra ${ }^{36}$ recintos amplios amurallados de vanguardia que en mi opinión son obra de al-Hakam II, puesto que son ignorados por las crónicas árabes de los tiempos de Abd al-Rahmán III, o de la política de reactivación de los puntos fronterizos llevada a cabo por su hijo. Y junto a Jaca hay otro Aseara, además del al-Askar de las proximidades de Huesca mencionado por al-Udri e identificado con la actual población de Angascara, según Fernando de la Granja ${ }^{37}$. Lo curioso de los dos leridanos, el de Vascos y el de Olite, es que fueron estudiados prácticamente hasta nuestros días como campamentos o

29. R. BURNS, «Los mudéjares de la Valencia de las Cruzadas. Un capítulo olvidado de la historia islámica», Sharq al-Andalus, 1, 1984, p. 22; y M.J. SOLER GARCÍA, «Noticias sobre moriscos en el Archivo Municipal de Villena», Sharq al-Andalus, 1, 1984, p. 73.

30. C. BARCELÓ, op. cit., Minorías.

31. A. GARCÍA Y Bellido, «El ejército romano en Hispania», Arch. Esp. de Arqueología, 49, 1976, pp. 59-113.

32. Op. cit., Muqtabis V, 81, 310, 314, 315, 320, 326.

33. Ibn Idari, Bayan II, Fagnan, Argel 1904, p. 300; L. TORRES BALBÁs, Ciudades hispanomusulmanas, I, Madrid, 1971, p. 66. Sobre la ciudad de Vascos, L. TORREs BALBÁs, Ciudades yermas hispanomusulmanas, Madrid, 1957; R. IZQUIERDO BENITO, «Excavaciones en la ciudad hispanomusulmana de Vascos -Navalmarolejo, Toledo-», Noticiero Arqueológico Hispánico, 7 y 16, 1979 y 1983.

34. V. MUQTABIS, op. cit., pp. 188 y 242-243.

35. J. GiRAlt i BALAGUERÓ, «Fortificacions andalusines a la Marca Superior: el cas de Balaguer», Setmana á arqueoligia Medieval, Institut d'Estudis Ilerdencs, Lleida, 1986, pp. 175 y ss.

36. B. CABAÑERO, «La medina islámica de Olite (Navarra). Claves para el estudio de su recinto amurallado», en La ciudad islámica, Zaragoza.

37. F. de la GRANJA, op. cit., p. 63, nota 2 . 
ciudades militares de época romana atendiendo a sus sillares almohadillados de induda- 
ble origen romano. Por último, Himyari da campamento de al-Askar, llamado también Qabtil, en los brazos del delta del Ebro, recibiendo ese nombre porque allí acamparon los normandos y construyeron un foso ${ }^{38}$. Queda patente que todos esos recintos amurallados son fronterizos. Pudiera acuñarse con todos ellos, parodiando los recintos ribats del siglo XII del Magreb, la expresión campamento-ribat por su ubicación fronteriza, y es precisamente tal carácter de límite de frontera lo que debió de precaracterizar o justificar estos al-askar-ribat, avanzadillas entre las marcas y entre curas. La desaparición de bastantes de ellos lo explica la pérdida de su función con el correr de los tiempos, pero casi siempre con un topónimo testigo adulterado; los no desaparecidos por su pervivencia como ciudades o lugares habitables residuales quizá hasta el siglo XII en que almorávides y almohades reestructuran militarmente todo Sharq al-Andalus y el lado opuesto de Extremadura y Portugal. Habría casos en que esos lugares adoptaron nuevos nombres.

Como quiera que fuere, la extinción física de la mayoría de los hábitats castrenses omeyas en muchos casos lo explicarían sus fábricas constructivas de tapial o flojas mamposterías, subsistiendo tan sólo los recintos de piedra bien escuadrada, Pla de Almatá, Vascos y Olite, además de Alguaire como caso excepcional de obra de tapial. Tal planteamiento conlleva reconocer en los primeros siglos de Sharq al-Andalus obras exclusivas de tapiería, con ausencia del sillar y aparejo omeya tipo cordobés, trascendiendo este hábito al siglo XII en que los muros de torres castilleras no rebasan en ningún caso el grueso de 1,30 o 1,50, quizá normativo en tapiería de la etapa omeya en esta zona y fortalezas jienenses, empezando por el castillo califal de Baños de la Encina, Segura de la Sierra y torre y muros de Aledo (población). La excepción en los muros de la torre de Villena, de más de tres metros de espesor y de un tapial hormigonado de inédita contextura por su reciedumbre en todo el Sharq al-Andalus, lleva a considerar tal construcción como pieza básica de la zona de no muy resuelta cronología. En principio, parecería hasta cierto punto lógico llevar los muros y torres de Ifach a la etapa califal, según propuesta de Bazzana, rellenándose así de contenido arqueológico ese lapso de los siglos IX y X en todo Sharq al-Andalus en lo que se refiere a sillares, intenciones también propuestas por el autor francés para el fortín que hubo en la cumbre del Almiserá, donde apareció cerámica omeya. La realidad es que en la zona de Levante sólo hay obra de sillería con aparejo omeya tipo califal en la torre atalayera o calahorra de Alpuente (Valencia), en la ruta castillera de Valencia-Cuenca ${ }^{39}$, fuera de la cura de Valencia de la que entraría a for-

38. Himyari; E. LeVI-Provencal, La Péninsule Ibérique au Moyen Age d'après le Kitab ar-Rawd al-Mi'tar fi habar al-aktar d'ibn Ábd al-Muním al-Himyari, Cairo, 1937, p. 135.

39. A. RiBerA i GomeZ, «El castell d'Alpont (Valencia)», Actas I Congreso de Arqueología Medieval Española, Al-Andalus, III, 1985. 
mar parte en el siglo XII, según Carmen Barceló. En este lugar los sillares se ven, además de la torre principal del castillo del Poyo, en muro colindante, mientras todo lo demás de la cumbre de la fortaleza es de mampostería y tapial, superpuestos, de acuerdo con las fábricas levantinas de los siglos XI y XII.

No se debe olvidar la desaparición radical de hábitats importantes de los beréberes Miknasa y Nafza de la parte de Badajoz, Umm Ya'far -Mojafar- y Umm Gaza -Magacela-, y la ciudad de Nafza, estudiados por Félix Hernández a partir de las fuentes árabes ${ }^{40}$, la última identificada con aquel Mojafar, según parece inferirse del Muqtabis $V$ de Ibn Hayyan y no con Vascos según propuesta de Félix Hernández. Volviendo a la piedra u obras de sillares en fortalezas o ciudades omeyas, parece que, siguiendo el ejemplo de Cartagena, en principio, serían antiguas reutilizadas, como aconteció con Iyi (h), según texto árabe recordado recientemente por Pocklington: "Murcia construida enteramente con los materiales de una ciudad romana de los alrededores" ${ }^{\prime 4}$; pero ese o parecido testimonio se da en el binomio Recupel / Zorita de los Canes, en la provincia de Guadalajara; dice al-Razí que la segunda se hizo con las piedras de la primera ${ }^{42}$, cuando en realidad Zorita a la luz de sus actuales murallas sólo enseña algún que otro fuste antiguo, romano o godo; y al hilo de esto, aunque en diferente contexto, dicen las fuentes escritas que Tarragona fue desmantelada por bárbaros o árabes no dejando piedra sobre piedra, cuando en realidad, como recordó Codera, esas murallas romanas están bien en pie. De todas formas es muy probable que Iyi (h) como ciudad antigua tuviera muros de sillares, pero lo de que éstos fueran trasladados a Murcia resulta un tanto hiperbólico, como en los dos casos reseñados.

\section{SOBRE ALBACARES}

Otro tema del que se habla mucho en cuestiones árabes y mudéjares alicantinas es el de la altura de las murallas de los albacares de los castillos islámicos. Epalza y Rubiera ${ }^{43}$ intentan rebajar la altitud de esas murallas periféricas porque básicamente eran construidas para encerrar ganados; pero hubo de todo y siempre pensando que los muros medievales nos llegan muy disminuidos. El muro formal o estatal de medinas y fortalezas de la campiña se sitúa

40. V. MUQTABis, op. cit., pp. 157, 193, 267; F. HERnÁNDEZ GiMÉNEZ, «Los caminos de Córdoba hacia el Noroeste en época musulmana», Al-Andalus, XXXII, 1967, pp. 97-119.

41. R. Pocklington, «El emplazamiento de Iyi (h)», Sharq al-Andalus, 4, 1987, p. 198.

42. Razi; E. LEVI-PROVENCAL, «Description de 1'Espagne d'Ahmad al-Razi», Al-Andalus, XVIII, 1953, p.80.

43. M. de EPALZA, «Funciones ganaderas de los albacares en fortalezas musulmanas», Sharq al-Andalus, 1, 1984, pp. 47-114; y M.J. RUBIERA MATA, La taifa de Denia, Alicante, 1985, p. 33. 
desde los tiempos de Roma entre 10 y 11 metros, pero en los campamentos romanos, según García y Bellido, la altura de sus murallas fluctuaba entre 3 y 4 metros; es decir, se trataba de muros obstáculos en hábitats poco estables. Se recuerda que los antemurales o barbacanas tenían esa misma altura, de 3 a 4 metros como mucho y que las puertas de éstos generalmente no tenían hojas para cerrar o abrir; son puertas sin mochetas. Esta modalidad se ve en el castillo alicantino de Ambra y en barbacanilla de la atalaya de los Rastros en las afueras de Badajoz, de época almohade. Al paso de esto se debe contar con que la ciudad campamento o militar de Vascos tiene muros de sillares y tapial que no suben más allá de los 4 ó 5 metros, y en la muralla de tapial de la Hoya de Almería la altura se establece en cinco metros como mucho. Los muros de Sharq al-Andalus, descontadas las torres atalayas con altitudes entre 13 y 20 por imposición almohade, eran casi siempre bajos, murallas obstáculos, señalizadoras del terreno acotado del castillo de la cumbre, las que, además, tenían su adarve y merlonado, entre otros casos el albacar del castillo murciano de Pliego. Por tanto, la función al unísono de albacar, refugio de ganado y muralla de protección militar a los efectos humanos era un hecho incontestable. La ausencia de construcciones en los albacares y también de restos cerámicos no lleva el tema a exclusivizarlo como territorio ganadero, porque se dan muchos casos con esas mismas ausencias pero con muros de adarves y merlones; y por lo general la población que va al albacar a ponerse a salvo no lo hace con carácter permanente, sólo temporalmente. Existen despoblados andalusíes de cierta envergadura y renombre en cuyos arrabales bien poblados han desaparecido por completo los restos de las casas simplemente porque fueron construidas con piedra y barro disimulado con capas de estuco, todo muy deleznable.

A título de propuesta, el término albacar o albacara muy de uso cristiano como denominación de territorio anexo del castillo o hisn, a veces de ciudades, pudo ser sustituto o sucedáneo del árabe "qawraya" y quizá también de "suluqiya"; el primero a juzgar por su uso cristiano -coracha- en mi criterio con varias acepciones, entre ellas corral o corralón del castillo, naturalmente amurallado. Y Suluqiyat -suluqia, suloqia, saloquia o Ceoquia- con acepción quizá de torre principal (en Pedro de Alcalá), y también espacio principal anejo o barbacana (Eguilaz y Yanguas), con menciones de esos probables significados en Ceuta árabe del siglo XV, según al-Ansari, Almenara o Celoquia en el castillo de Sagunto, torre de la alcazaba de Silves y en Toledo mención de sinagoga de Suloqia. Acepción probable de suluquia es torre albarrana que se desconoce en Sharq al-Andalus, exceptuada una del castillo de Corbera estudiado por Bazzana $^{44}$ y probablemente otra almohade de las murallas de Murcia, cuya lápida fundacional leída y comentada por Levi-

44. A. BAZZANA, «Elements d'archeologie musulmane dans al-Andalus: caracteres specifiques de l'architecture militaire arabe de la region valencianne», Al-Qantara, I, 1989, pp. 339-363. 
Provençal da su altura de hasta 20 metros, propia como se vio de atalayas pero no de torres normales de murallas, con altitud máxima de 13 metros como mucho.

\section{MATERIALES Y PROCEDIMIENTOS CONSTRUCTIVOS}

Respecto a los materiales y procedimientos constructivos en Sharq al-Andalus, tras estudios de Torres Balbás, los míos, los castilleros de Azuar Ruiz, de Guichard-Bazzana-Cressier, Segura i Martí, Torró i Abad, Menéndez Fueyo y otros, la arqueología se encuentra prácticamente en un callejón sin salida para el tramo de los siglos IX, $\mathrm{X}$ y XI. Fábricas y procedimientos son híbridos, mixtos, ambiguos, con predominio del tapial o tabiya y muros encofrados a los que se asocia la mampostería de fajeado muy regular, horizontal y de la altura de un canto normal de 0,20 a 0,25 metros aproximadamente, con lajillas o sin ellas como verdugadas niveladoras por lo general como zócalo de la tabiya. Así se dan tres procedimientos básicos. Uno, la tabiya con mechinales; dos, superposición de mampostería y tapial -encima-; tres, muro hormigonado sin mechinales con paramento de leve estucado en los que ha quedado impresa la huella de las tablas del encofrado. Son tres procedimientos que lejos de ser autóctonos de Sharq al-Andalus tienen raíces ancestrales y se dan en todo el al-Andalus, que los recibió de la Antigüedad. La mampostería de fajeado regularizado, a veces con cantos inclinados, espiguilla o "espicatum", que algunos autores han calificado de beréber, se da mucho en la Marca Media desde el siglo X -provincias de Soria, Guadalajara y Cuenca-; en Levante se ve por vez primera en la Rabita de Guardamar, muralla de Elche paralela del Vinalopo, Orihuela -castillo-, muro de Cocentania sobre el cerro de la atalaya, y fortalezas de Aspe, Callosa de Segura y Castalla. En Andalucía se registra en Guadix -muralla de la población-, Gafiq, restos de muro dentro del castillo de Jorquera (Albacete), castillo de Alcaudete de Jaén y Vilches; debió darse en lo primitivo de Ronda. Almorávides y almohades siguieron utilizándola en el Magreb, castillo de Amergó, muralla de Taza, ribat de Tit, despoblado de Dchira; y en Andalucía en proporciones y lugares muy variables. Así, al margen de las construcciones cristianas, al-Andalus tuvo como propias murallas de fajeado estrecho bien regularizado con cronología inicial en el siglo X y el XI.

Los tapiales registran en Sharq al-Andalus las modalidades siguientes. Tapial con mechinales con las agujas metidas en obra no más de 0,50 metros de profundidad. Usualmente la tapia tiene gran proporción de canto grande sobre todo en fortalezas o murallas junto a un río -Elche, muralla junto al río de Orihuela con la torre hexagonal Emberergoñés, Castillejo de Murcia, Chelva, Elda-, añadiéndose muros de la provincia de Jaén, Segura de la Sierra, Hornos, Iruela, Santiesteban. Sobresalen por su reciedumbre los muros de las torres de Aledo, Villena, Mariola, aljibe del castillo de Orihuela, 
muralla de Játiva y la de Murcia, los que por semejante consistencia se asocian a murallas del castillo de Baños de la Encina, restos de muros de Quesada, muro del interior del castillo de Segura de la Sierra, restos de muros del Albaycín de Granada y parte inferior de la muralla norte de la alcazaba de la Alhambra, muralla del Vacar de Córdoba, restos muros de Baza y muralla urbana de Guadix. Se podría hablar en todas esas fábricas de tapiales hormigonados. Otra modalidad, paramentos de 15 a 20 metros de espesor de consistente textura y estucado el exterior, con tierra prensada en el núcleo -Monteagudo, muralla de Sagunto, castillo de Tabernas (Almería) y torres de Fez Jdid-. Por último, tapiales sin mechinales a la vista, en Monteagudo y el Castillejo de Murcia y en la muralla de esta ciudad de la parte de la puerta de Santa Eulalia. Los orígenes se adscriben a lo romano -Ampurias y Volúbilis-; García y Bellido dice que campamentos romanos de la parte de Soria y Sigüenza tenían defensas de tierra con foso delante; califal, en Pla d'Almatá, Vascos, Baños de la Encina, el Vacar de Córdoba, murallas del siglo IX de Badajoz y Toledo, según las crónicas árabes, murallas de Fez del siglo X, según al-Mugaddasi, murallas del Albaycín de Granada y zona inferior de la muralla norte de la alcazaba de la Alhambra.

El hormigón o mortero sin mechinales y con huellas a veces de las tablas horizontales en el paramento estucado, encofrado, es registrado en torres de la muralla urbana de Alpuente, en Chelva, Chera y castillo de Olocau, Bairen, junto a Gandía, y Alcalá de Montserrat, entre otros ejemplos; tiene precedentes en muros del siglo X-XI de las Marcas Superior y Media: muralla del castillo principal de Calatayud, torre del castillo de Daroca, torre de Alcalá la Vieja (Alcalá de Henares), Torre Vieja de la alcazaba de Badajoz, torres de Segura de la Sierra y de Hornos, y castillo de Tiscar (Jaén). En Córdoba, en el núcleo de puentes y acueductos califales así como albercas en el camino de Córdoba a Madinat al-Zahra. La superposición de mampostería, zócalo y tapial está representada en los castillos de Orihuela, Callosa de Segura, Aspe, Alpuente, la Mola, Cortes de Pallás, Calahorra de Elche, Castalia de Castellón, Busot, Castalla de Alicante, Ricote, Mula, Alcalá de Benisili, castillo de Cieza, muralla urbana de Aledo y, según las crónicas árabes, en Valencia. En esta ciudad han aparecido lienzos de muralla con mampostería con zarpas en la base y tapial de mortero encima con enlucido blanco ${ }^{45}$. Se ven paralelos en muralla de Velefique y Huebros (Almería); atalaya de Toya, en Jaén; castillo de Alora y recinto de Salia, en Málaga; castillos de Montemolín y Reina, en Extremadura; recinto de Gafiq, en Córdoba, y Albalate, de Cáceres. Se remontan los orígenes a Ampurias y Volúbilis, pasando por el periodo omeya, donde el zócalo es de sillares -Pla d'Almatá y

45. R. SORIANO SÁNCHEZ y J. PASCUAL PACHECO, «Aproximación al urbanismo de la Valencia medieval», Urbanismo medieval del país valenciano, Madrid, 1993. 
Vascos-, sin descartar Sijilmasa, en el Sur de Marruecos, con zócalo de piedra y encima ladrillos secados al sol que con el tiempo sería tierra. Las murallas más resistentes de tapial hormigonado a veces no precisan de zócalos de piedra o mampostería, desde lo califal, con ejemplos en Baños de la Encina y en el Vacar de Córdoba.

A todos esos procedimientos constructivos de clasificación no siempre coincidentes en distintos autores o tratadistas actuales, se suman los siguientes recursos. I) Sillares simulados al exterior de murallas de tapial: castillos de la Mola, Villana -torre-, castillo de Cortes de Pallás, Elda y otras torres atalayas con los paramentos muy desgastados, como la primitiva torre del castillo palacio de Forna. Hacen acto de presencia en el castillo de Baños de la Encina, el Vacar de Córdoba y todo lo almohade del Magreb, murallas y torres de Sevilla, castillos y fortalezas del Algarbe portugués, Extremadura y castillos onubenses; por último muralla almohade de la alcazaba de Túnez. 2) Zarpas al pie de las torres: torre de Aledo, Mariola, Monteagudo, el Castillejo de Murcia, castillo de la Luz de Murcia -tres zarpas superpuestas-, Alhama de Murcia, atalayas de Valencia y Alicante, la gruesa de Forna con múltiples zarpas; Valencia y Chera de Valencia. Arranca su uso en castillo de Baños de la Encina y el Vacar de Córdoba, murallas del Albaycín de Granada y muralla norte de la alcazaba de la Alhambra, generalizándose en lo almohade de Rabat y Marrakech y fortalezas del sur de Portugal, Extremadura, Sevilla y Huelva; siguen en la Alhambra. Los muros omeyas de piedra se distinguían por el uso a veces abusivo de zarpas superpuestas, con progresiva ascensión desde los cimientos, nunca con la pendiente o rampilla que se vio en torres de Ifach. 3) Talud muy prolongado al pie de las torres: no se ve en Sharq al-Andalus; eran usuales en torres almorávides-almohadas de Rabat y Marrakech; y es probable que los almohades añadieran talud a las torres califales del castillo de Tarifa. 4) Líneas hendidas en zigzag en paramentos estucados, exteriores o interiores; en Levante se ven en interior de torre del castillo de Olocau, algunos aljibes alicantinos y valencianos, como el del castillo de Confrines, interior de la torre de Benifallim. Aparecen ya en el castillo de Baños de la Encina, muralla del primer recinto de la alcazaba de Almería, castillo de Piñar, muralla de Taza y muros del Afrag de Ceuta y en Belyunes. Respecto a orígenes, los usaron los romanos dejándose ver en muralla estucada de Lixus y en muro de Astorga (León). 5) Sillares o sillarejo bien escuadrados en las esquinas de torres de mampostería de fajas horizontales reguladas: sólo registrado en torres del castillo de Orihuela con paralelo en el Alcázar almorávide de Marrakech, recinto almorávide-almohade de Dechira y alcazaba de Gnaoua, en Marruecos. 6) Saeteras de debajo de los merlones: muralla del castillo de Castalla y Alcalá de Benisili. Aunque pudieron existir en el castillo de Baños de la Encina fueron los almohades los que las pusieron en vigor a esa altura en todo al-Andalus y en el Magreb. No aparecen merlones de cuño almohade con intervalos formando en la base dos rebajes curvos a los extremos y prominencia redondeada en medio, pero 
según viejas descripciones de las murallas de tapial de la población de Cocentaina, en el llano, pudo haber aquí ese tipo de merlón. 7) Torres hexagonales: una en la muralla junto al río de Orihuela -torre Embergoñés- y otra en la muralla urbana de Alpuente, y la del castillete de las Navas de Tolosa; con precedentes en Marrakech, Fez y Rabat, tal vez la torre de Santo Tomás de Sevilla. 8) Torrecilla doble formando ángulo recto en la esquina de murallas: castillo de Monteagudo y el Castillejo de Murcia, con paralelo en el castillo cordobés de Azur; se ha señalado como precedente el palacio preislámico de Pla de Nadal, en Valencia. 9) Mampostería de fajas estrechas regularizadas con verdugadas de ladrillo: caso único en zócalo de muralla de tapial de Murcia, con paralelo en lienzos de las cercas almohades de Andújar y Jerez de la Frontera, y torre añadida a la muralla urbana de Guadix. Este tipo de mampostería se da en las alcazabas de Málaga y Badajoz, además de Niebla y castillo de Aroche, torre de Alcalá de los Gazules (Cádiz) y la Alhambra. 10) Agujeros en los muros, inclinados hacia afuera y circulares, pudiéndose identificar como buhedera, lanzaderas para derramar líquidos, según se ven en la barbacana conservada de Sevilla, castillo de Planes de Alicante y muralla de Valencia; esos orificios los detectó Azuar en muralla del castillo de Orihuela, aquí quizá como recibo de maderos de adarve o cadalso leñoso interior improvisado que se ve en torres huecas almohades de Rabat y se encuentran en algunas torres atalayeras de la parte de Almería; se ven también en la barbacana del castillo toledano, cristiano, de Almonacid. 11) Indiscutible es la imposición en Sharq al-Andalus por los almohades de antemurales, puertas en codo y torres albarranas; los primeros en los castillos de Ambra, Planes, Perpusent; la puerta en codo en esas mismas fortalezas y la albarrana quizá en las murallas de Murcia, además del castillo de Corberá. 12) No se registra en Sharq al-Andalus torres de tapial con esquinales de ladrillos usuales en la Andalucía occidental y en Extremadura. 13) Muros inclinados, modalidad que se deja ver en torres del castillo de Orihuela y algunas torres atalayas alicantinas.

De toda la anterior descripción a título de inventario provisional lo único que se pone de manifiesto es que Sharq al-Andalus participó en su amplia trayectoria árabe de las mismas modas edilicias y arte poliorcético de todo al-Andalus, por lo que habría que desechar de toda esta zona la tesis muy consensuada hasta ahora de arquitectura autóctona. Son contadas las fortalezas andalusíes que tienen el sello de piedra omeya tipo Córdoba o Madinat al-Zahra, sin duda por razones económicas suplidas por una arquitectura provincial o popular de gremios o tribus. La mampostería de fajas estrechas y bien reguladas, con cantos a modo de pseudotizón enhiestos o inclinados, contando con los paralelos enunciados, pudiera llevarnos a la transición de los siglos X y XI. Los tapiales y la obra mixta de mampostería y tapial es cierto que acusan facturas almohades refrendadas muchas veces por citas en las crónicas árabes y restos cerámicos a pie de obra, pero esas técnicas constructivas debieron de darse en la etapa omeya, contribuyendo a 
reforzar esta creencia la ausencia de sillería formal de cuño califal cuando al parecer los mandatarios omeyas tratan de poner orden en Levante; es posible que las rebeldías continuas de la zona llevaran a aquéllos a desmantelar determinadas fortalezas, causa de la pérdida o erradicación de hábitats importantes, cual es el caso de medina al-'Askar.

En la ya vieja contienda de tapial almohade y tapial omeya lo único que queda como testimonio para debatir en pro del segundo es la fortaleza de Callosa de Segura y la de Orihuela, bien planteadas o intuidas en estudios de Azuar, además de la recia contextura de los tapiales de las torres de Aledo, Villena, Mariola, Penáguila y muralla de Játiva, donde como caso excepcional aparece una torre semicircular de tapial, a imitación de las tres de la muralla del Albaycín de Granada; también hay torre redonda de tapial en las murallas de Tremecén, de época meriní. Queda probado que la altura de la tapia es la misma en las etapas omeya y almohade, en torno a los 0,85 metros, y esa misma uniformidad se da en los sillares fingidos. No es rasgo diferenciador que un tapial tenga 0,80-0,85-0,90 e incluso 1 metro. Quizá algunas tapias entre 0,60 y 0,80 registradas en contados casos -Granada y provincia de Alicante- sean síntomas de mayor antigüedad. En todo al-Andalus y el Magreb la tapia es uniforme con ese breve escalonamiento de guarismos advertido en otras regiones. La asociación tapial y torre de hasta 20 metros de altura es síntoma seguro de "almohadización". La postura más lógica es que los castillos de Sharq al-Andalus mencionados en Ibn Hayyan, al-Udri e Idrisi serían desde el siglo $\mathrm{X}$ de tapial o de mampostería y tapial, con una gama de fabricación que Bazzana clasifica en tres apartados: tabiya de tierra, tabiya de mortero y tabiya de piedra.

Esto fue así en Sharq al-Andalus dándose larga pervivencia de la tabiya y el encofrado, al igual que en el resto de al-Andalus -y en el Magreb-, desde la etapa omeya sobrepasando la línea de la reconquista, pues los mudéjares, remodeladores de muchos castillos árabes, no disponían de otros procedimientos constructivos a la vista; con los cristianos se reanima el sillar y el sillarejo por lo general apaisados.

\section{CONCLUSIÓN}

Volviendo al punto de partida de este trabajo, personalmente me inclino a prestar más atención a Mascarat que a Ifach desde el punto de vista castrense oficial, gubernamental o estatal. Sobre la supervivencia en esta zona alicantina del término Calpe en lugar de Mascarat, la sospecha lógica es que el primero es de origen clásico o romano bien enraizado y posterior o árabe el segundo, implicando aquél vieja y amplia territorialidad mientras Mascarat, como dijimos, sería residual topónimo de tierra adentro. Tal posición dentro de la Marina alicantina y apartado de la vieja Vía Augusta ha extrañado a historiadores de los últimos lustros. De todas formas en toda esta 
tierra, entre Toix e Ifach se puede hablar de transacciones demográficas o población errática en una y otra dirección. De momento, a mi entender, son expresiones árabes, quizá clásicas o latinas arabizadas, Qalb y Mascara; matizando, respecto a la segunda, que los árabes pudieron en ocasiones llamar al-Askar a viejos campamentos en desuso desde época tardorromana. De otra parte no debería verse en la voz al-Askar levantina expresión de un lugar único, ya que se trata de un término que se repite a veces en una determinada región o comarca, empezando por Ifriqiyya, donde se repite tres veces, en Huesca dos, una en Zaragoza, otra en la desembocadura del Ebro; en Levante medinat al-Askar -cora de Tudmir- y aquel Alasquer próximo a Valencia: no veo razones de peso para pensar que se trata de uno mismo. Por último, al-Muqqggadasi dice que en la ciudad de Sijilmasa (Marruecos), fundada entre los siglos VIII y IX, había en el centro fortaleza llamada al-askar con mezquita y palacio del emir dentro, lo que confirmaría lo de una ciudad llamada al-Askar en la cora de Tudmir o Umm al-Askar. De todas estas reflexiones pudiera inferirse que al-Askar sería en el caso alicantino lugar de acampada fronterizo y de montaña en el límite de las coras de Valencia y Tudmir, quizá de época califal, que en ningún caso cabe confundir con el despoblado del istmo del Peñón de Ifach, cuyas murallas y torres en mi criterio son cristianas o mudéjares sin descartar que allí hubiera hábitat musulmán a continuación del ibérico romano o del siglo V-VI por sólidas razones derivadas de la naturaleza rocosa del peñón configurado como fortaleza natural. Pero esta avanzadilla rocosa metida en el mar, sometida a las envestidas de los piratas del Mediterráneo en todo tiempo, arrojó un hábitat de sobresaltos continuos y paralización, la última registrada a lo largo del siglo $\mathrm{XV}$, dando lugar a la fundación en la siguiente centuria del fuerte del actual Calpe.

Respecto al dilema de los dos Callosa alicantinos, abundando en la hipótesis al-Askar $=$ Callosa d'En Sarrià, ciudad e iqlim, parece lógica frente al-Askar = Callosa de Segura, por quedar esta localidad dentro del iqlim de Murcia o quizá del iqlim de Orihuela propuesto por Molina López; siendo así este Callosa estaría de siempre eclipsado por Orihuela como lo estuvo en la dominación cristiana, a partir del año 1298 en que se menciona el lugar por vez primera; el Callosa de Ensarría, como se vio, se cita en 1264, así como en su término la alquería de Muscayra.

\section{Post Scriptum}

Referente al término "Mascarat", en Sevilla, región de Gines, se localizan un "Mascarat" y una cuesta llamada "Macareta". Con manifiesto retraso me entero de dos básicas y concluyentes aportaciones que proporcionan M.J. Rubiera / Mikel de Epalza: en al zona de Callosa d'En Sarrià una 'Serra d'Alaskar (1276) y una alquería llamada "Beniascher (1244) = Bina'Askar = Bani'Askar. Añaden dichos autores: el topónimo Mascarat se parece sospe- 
chosamente al árabe ma'askara, "campamento" (con lt final por influencia del catalán y de la leyenda del "enmascarado") como para que no lo juntemos a los dos topónimos anteriores". (Los nombres árabes de Benidorm y su comarca, Alicante, 1985, pp. 43-51).

\title{
RESUMEN
}

Estudios y reflexiones arqueológicas sobre el Peñón de Ifach de Calpe (Alicante), con restos de muralla y torres de los siglos XIII y XIV, y la voz árabe al 'Askar que las Crónicas árabes del siglo $\mathrm{X}$ aplican a una ciudad campamento (Madinat al 'Askar). Se insiste en la tesis de M.J. Rubiera / M. de Epalza y otros autores que sitúan esa ciudad en la amplia comarca del actual Callosa d'En Sarrià, donde se registran topónimos cristianos (s. XIII) derivados de al 'Askar árabe del siglo X. En esa comarca se encuentran restos de cerámica vidriada tipo califal.

\begin{abstract}
Archaeological studies and reflections above Ifach Rock at Calpe (Alicante) with walls and towers remains of the Thirtteen and Fourteen centuries, and the Arab Voice al 'Askar which refering to the Tenth century islamic chronicles are identified with a town-camping (Madinat al 'Askar). According to M.J. Rubiera / M. de Epalza and other authors' thesis, I insist on the idea that madinat al 'Askar is a wide district of the present village Callosa D'En Sarrià. Here appear islamic glazed ceramics remains of the Tenth Century and also Christian place-names (XIII C.) derived from the islamic al 'Askar.
\end{abstract}



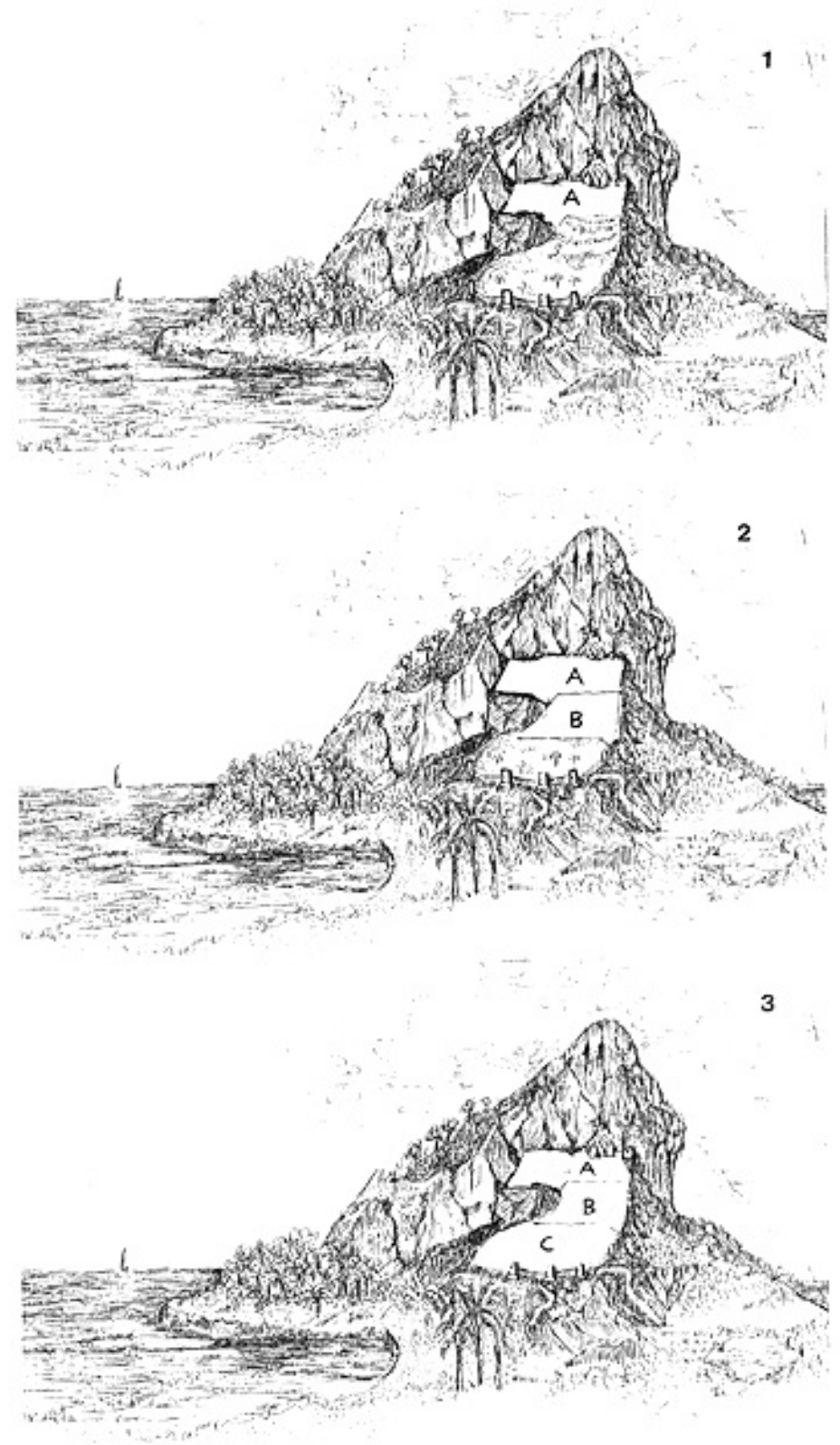

Fig. 1. El Peñón de Ifach. Supuesto proceso de población. 1. Hábitat A: ibero-romano-bizantino; 2. Expansión árabe en $\mathrm{B} ; 3$. Nueva expansión en $\mathrm{C}$. En la repoblación cristiana se acotaron con muros los recintos A, B y C. Apuntes de B. Pavón. 


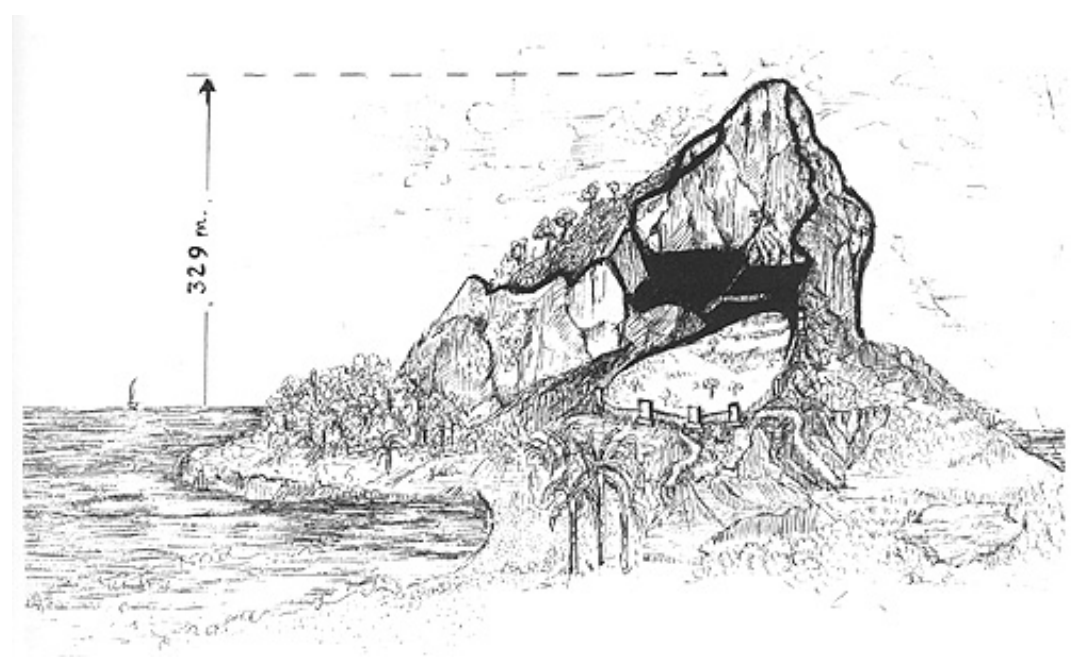

Fig. 2. El Peñón de Ifach. Subrayado en negro las partes inaccesibles o de defensa natural. Apunte de B. Pavón.
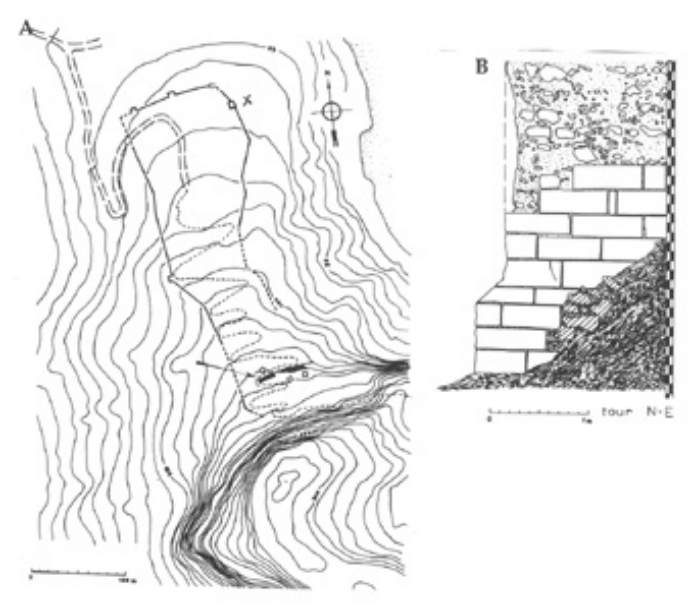

Fig. 3. A. Plano de Bazzana del istmo del Peñón de Ifach; B. Torre (en el plano X), según Bazzana. 


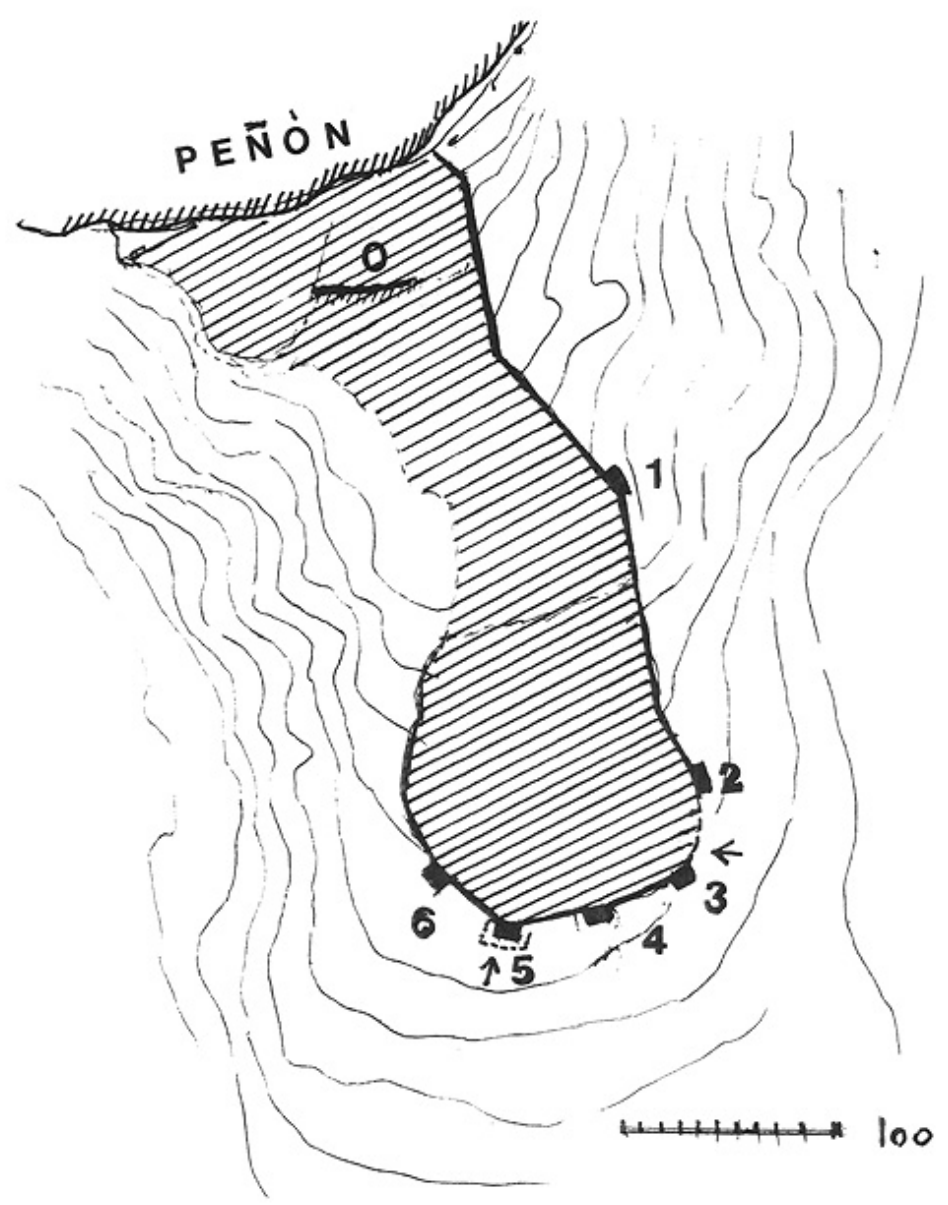

Fig. 4. Muralla del istmo del Peñón de Ifach; reutilizado el plano de Aranegui-Bazzana, con supuestas puertas añadidas entre las torres 2 y 3 y en la torre 5. Las torres nuevas añadidas son la 2 y la 5; la 6, estudiada por Bazzana, tiene sillares en la base y encofrado en la parte superior. La muralla $\mathrm{O}$, localizada como preislámica en excavaciones y prospecciones anteriores a Aranegui-Bazzana. 


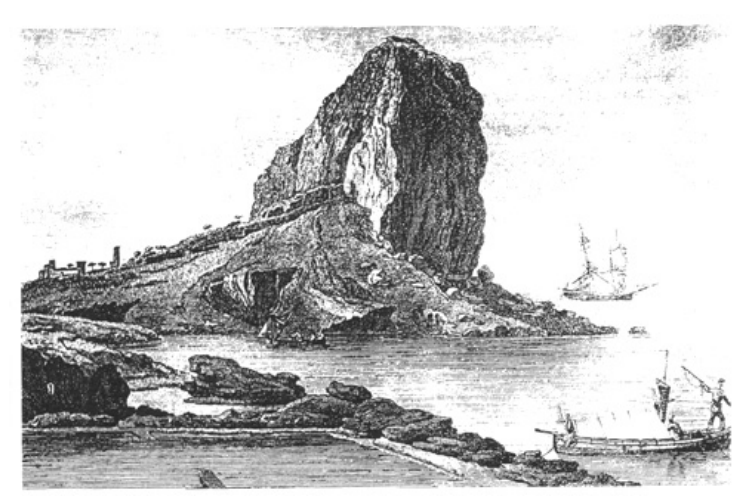

Fig. 5. El Peñón de Ifach, según Laborde; con restos de muralla y torres del istmo.

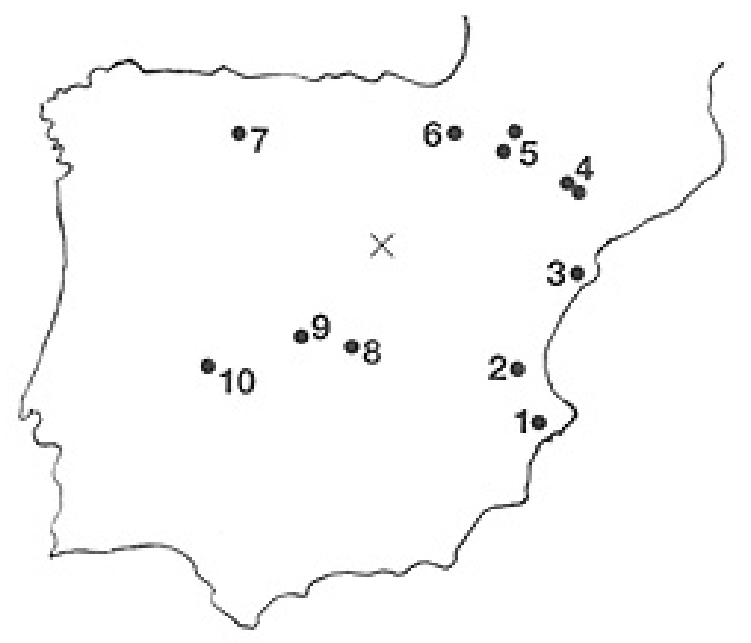

Fig. 6. Localización de "al-Askar". 1. Madinat al-Askar de Alicante; 2. Alasquer de Valencia; 3. Al-Askar del delta del Ebro; 4. Campamentos estables de Pla d'Almata y Alguaire (Lérida); 5. Al-Askar, por Jaca, y al-Askar (angascara), en Huesca; 6. Olite (Navarra); 7. Almazcara (León); S. Masqaraque (Toledo); 9. Talavera y despoblado de Vascos (Toledo); 10. Supuesto emplazamiento de Saktán (Cáceres). X. Campamento al-Askar de Zaragoza. 